\title{
Comment on "Breast implant-associated anaplastic large cell lymphoma: the first South Korean case"
}

\author{
Il-Kug Kim, Tae Gon Kim \\ Department of Plastic and Reconstructive Surgery, Yeungnam University College of Medicine, Daegu, Korea
}

\section{Dear Editor,}

We read the paper, "Breast implant-associated anaplastic large cell lymphoma: the first South Korean case," with great interest [1]. The authors described a Korean case of breast implant-associated anaplastic large cell lymphoma (BIA-ALCL), including the clinical manifestations and pathologic features. They claimed that it was the first South Korean BIA-ALCL case. However, to our understanding, this is not true. One of the co-authors of the paper, Dr. Eun Key Kim, presented this case at the Breast Reconstruction Symposium held on June 10, 2020, and described the case as "the second BIA-ALCL case in Korea" [2]. The first case of BIA-ALCL in Korea was a 44-year-old female patient diagnosed and treated at Yeungnam University Medical Center in August 2019, and the case was presented on November 9, 2019, at the 77th PRS KOREA, the main academic conference organized by the Korean Society of Plastic and Reconstructive Surgeons [3].

The first case of BIA-ALCL in Korea led to several important changes for plastic surgeons. After the first BIA-ALCL case was reported, all hospitals in Korea stopped using textured breast implants and switched to smooth breast implants. Moreover, Korean medical insurance does not cover the treatment for any complications of uninsured cosmetic surgery. BIA-ALCL is regarded as one such complication. Without insurance, the cost of BIA-ALCL treatment is an excessive burden on most patients. Hence, the medical staff and the Korean Society of Plastic Surgeons requested the Health Insurance Review and Assessment Service to cover BIA-ALCL, and it was approved. As such, the

Received: August 16, 2021 Accepted: September 21, 2021

Corresponding Author: Tae Gon Kim, MD, PhD

Department of Plastic and Reconstructive Surgery, Yeungnam University College of Medicine, 170 Hyeonchung-ro, Nam-gu, Daegu 42415, Korea

Tel: +82-53-620-3480, Fax: +82-53-626-0705, E-mail: kimtg0919@daum.net first case of BIA-ALCL in Korea is a meaningful and memorable case for all plastic surgeons.

The case report of the first case of BIA-ALCL in Korea was published online in December 2020 and published in print in April 2021 [4]. Molecular analysis and histopathologic analysis were performed, although these were time-consuming. Meanwhile, the authors published the second case of BIA-ALCL in Korea as the first case. This may be the first published case report but it is not the first identified case [1]. Hence, in our opinion, this should be amended.

\section{Ethics Statement}

Not applicable.

\section{Availability of Data and Material}

Data sharing not applicable to this article as no datasets were generated or analyzed during the study.

\section{Code Availability}

Not applicable.

ORCID

Tae Gon Kim https://orcid.org/0000-0002-6738-4630

Il-Kug Kim https://orcid.org/0000-0002-2428-8403

\section{Author Contributions}

Conceptualization: IKK, TGK. Writing-original draft: IKK. Writing-review \& editing: IKK, TGK. Approval of final manuscript: all authors.

\section{Conflicts of Interest}

The authors declare that they have no potential conflicts of interest.

\section{Funding Statement}

No funding to declare.

\section{References}

1. Lee J, Cho H, Yoon DH, et al. Breast implant-associated anaplastic large cell lymphoma: the first South Korean case. J Pathol Transl 
Med 2020; 54: 432-4.

2. Kim EK. The second BIA-ALCL case in Korea. In: The Symposium of Korean Academic Association of Aesthetic and Reconstructive Breast Surgery; 2020 Jun 10.

3. Kim IK. Clinical report of the first Korean case of BIA-ALCL. In:
PRS KOREA 2019; 2019 Nov 8-10; Seoul, Korea.

4. Kim IK, Hong KY, Lee CK, et al. Analysis of the molecular signature of breast implant-associated anaplastic large cell lymphoma in an Asian patient. Aesthet Surg J 2021; 41: NP214-222. 